\title{
Continuous fictitious play in zero-sum games
}

Citation for published version (APA):

Driesen, B. W. I. (2009). Continuous fictitious play in zero-sum games. METEOR, Maastricht University School of Business and Economics. METEOR Research Memorandum No. 049 https://doi.org/10.26481/umamet.2009049

Document status and date:

Published: 01/01/2009

DOI:

10.26481/umamet.2009049

Document Version:

Publisher's PDF, also known as Version of record

\section{Please check the document version of this publication:}

- A submitted manuscript is the version of the article upon submission and before peer-review. There can be important differences between the submitted version and the official published version of record.

People interested in the research are advised to contact the author for the final version of the publication, or visit the DOI to the publisher's website.

- The final author version and the galley proof are versions of the publication after peer review.

- The final published version features the final layout of the paper including the volume, issue and page numbers.

Link to publication

\footnotetext{
General rights rights.

- You may freely distribute the URL identifying the publication in the public portal. please follow below link for the End User Agreement:

www.umlib.nl/taverne-license

Take down policy

If you believe that this document breaches copyright please contact us at:

repository@maastrichtuniversity.nl

providing details and we will investigate your claim.
}

Copyright and moral rights for the publications made accessible in the public portal are retained by the authors and/or other copyright owners and it is a condition of accessing publications that users recognise and abide by the legal requirements associated with these

- Users may download and print one copy of any publication from the public portal for the purpose of private study or research.

- You may not further distribute the material or use it for any profit-making activity or commercial gain

If the publication is distributed under the terms of Article $25 \mathrm{fa}$ of the Dutch Copyright Act, indicated by the "Taverne" license above, 


\section{Maastricht University}

Bram Driesen

Continuous fictitious play in zerosum games

$\mathrm{RM} / 09 / 049$

\section{METEOR}

Maastricht University School of Business and Economics

Maastricht Research School of Economics

of Technology and Organization

P.O. Box 616

NL - 6200 MD Maastricht

The Netherlands 


\title{
Continuous Fictitious Play in Zero-Sum Games
}

\author{
Bram Driesen*
}

This version, October 2009

\begin{abstract}
Robinson (1951) showed that the learning process of Discrete Fictitious Play converges to Nash equilibrium in two-player zero-sum games for any initial condition. In several earlier works, Brown $(1949,1951)$ makes some heuristic arguments for a similar convergence result for the case of Continuous Fictitious Play (CFP). The standard reference for a formal proof is Harris (1998); his argument requires several technical lemmas, and moreover, involves the advanced machinery of Lyapunov functions. In this note we present a simple alternative proof. In particular, we show that Brown's convergence result follows easily from a result obtained by Monderer et al. (1997).
\end{abstract}

JEL-Classification: C72, D83

Keywords: Fictitious play; Zero-sum games.

\section{Introduction}

Fictitious Play is a procedure in which at each instance, players of a game myopically play their best replies against the opponents' past play. The origins of Fictitious Play lie in a series of papers by Brown $(1949,1951)$ and Robinson (1951). While today, the algorithm is usually interpreted as a myopic learning process, the initial objective of these studies was to develop an easy method to find the value of zero-sum games. In his 1949 article, Brown already argued heuristically that the continuous version of the procedure - Continuous Fictitious Play (CFP) - must converge at a linear speed to the set of Nash equilibria, and thus, the value of the game. This result is again mentioned - without proof - in Brown (1951). Brown's to a large extent heuristic approach towards CFP may be explained by the fact that he was primarily interested in a discrete algorithm, and thus, only considered convergence of CFP in zero-sum games

*Department of Quantitative Economics, University of Maastricht, P.O. Box 616, 6200 MD Maastricht, The Netherlands. Telephone: +31-43-3883835. Telefax: +31-43-3884874. Email adress: B.Driesen@maastrichtuniversity.nl 
as support for his conjecture that Discrete Fictitious Play (DFP) in zero-sum games converges to equilibrium.

The proof of this conjecture was obtained by Robinson (1951) in the early fifties. However, it was not until Hofbauer (1994) and Harris (1998) that the result for CFP was rigorously proven. Today, Harris' proof has become the standard reference. Essentially, he shows that the sum of players' instantaneous improvement steps in a zero-sum game, is a Lyapunov function. While this argument appears to be quite simple at first glance, it requires several rather technical lemmas ${ }^{1}$. Moreover, it makes use of non-trivial results on dynamical systems. Different versions of Harris' proof - often in a simplified form - have appeared in the literature. See a.o. Krishna and Sjöström (1997), Shamma and Arslan (2004), and Hofbauer and Sorin (2006).

In this note we provide a simple alternative argument. We show that the convergence of CFP in two-player zero-sum games follows trivially from a result obtained by Monderer et al. (1997) that says that for CFP in any game, each player's instantaneous expected payoff will in the long run coincide with the average payoff that player has realized so far. Using the same approach, convergence of DFP is established up to the condition of infrequent switching (Fudenberg and Levine, 1994; Monderer et al. 1997). That is, if for DFP in a zero-sum game players play each pure strategy profile for increasingly long periods of time, then the DFP converges to equilibrium. Simulations lead us to conjecture that infrequent switching is the engine behind Robinson's result ${ }^{2}$. Whether DFP in zero-sum games satisfies the condition of infrequent switching in general, remains an open question.

\section{Preliminaries}

\subsection{Zero-sum Games}

A zero-sum game is represented as an $m \times n$ matrix $A$. There are two players - 1 and 2. Player $1[2]$ has a pure strategy set $I[J]$ of cardinality $m[n]$. If player 1 plays strategy $i$ and 2 plays $j$, then player 1 receives a payoff of $a_{i j}$ and 2 of $-a_{i j}$. Let $\Delta^{m}$ and $\Delta^{n}$ be the sets of probability distributions over sets of respectively $m$ and $n$ alternatives; $\Delta^{m}$ and $\Delta^{n}$ are players' respective sets of mixed strategies over $I$ and $J$. A pure strategy $i \in I$ is also denoted as the unit vector $e^{i} \in \Delta^{m}$; we write $\tilde{I}:=\left\{e^{i} \mid i \in I\right\}$. Analogously, we denote player 2's $j$-th pure strategy also as the $j$-th unit vector $f^{j} \in \Delta^{n}$, and $\tilde{J}:=\left\{f^{j} \mid j \in J\right\}$. Let $\beta_{1}: \Delta^{n} \rightarrow \Delta^{m}$ be player 1's best-reply correspondence. That is,

$$
\beta_{1}(\hat{q}):=\left\{p \in \Delta^{m} \mid p A \hat{q} \geq p^{\prime} A \hat{q} \text { for all } p^{\prime} \in \Delta^{m}\right\} .
$$

Player 2's best-reply correspondence, $\beta_{2}: \Delta^{m} \rightarrow \Delta^{n}$ is defined as

$$
\beta_{2}(\hat{p}):=\left\{q \in \Delta^{n} \mid \hat{p} A q \leq \hat{p} A q^{\prime} \text { for all } q^{\prime} \in \Delta^{n}\right\} .
$$

\footnotetext{
${ }^{1}$ See also Hofbauer and Sorin (2006).

${ }^{2}$ Note that convergence of CFP implies convergence of DFP for a class of games that includes zero-sum games. See Harris (1998) and Hofbauer and Sorin (2006).
} 
Define $\beta: \Delta^{m} \times \Delta^{n} \rightarrow \Delta^{m} \times \Delta^{n}$ as $\beta(p, q):=\left(\beta_{1}(q), \beta_{2}(p)\right)$. The set of Nash equilibria of a game $A$ is defined as

$$
N E(A):=\left\{(p, q) \in \Delta^{m} \times \Delta^{n} \mid(p, q) \in \beta(p, q)\right\} .
$$

That is, $N E(A)$ is the set of fixed points of the best-reply correspondence $\beta$. Define the function $W: \Delta^{m} \times \Delta^{n} \rightarrow \mathbb{R}$ as

$$
W(\hat{p}, \hat{q}):=H(\hat{q})-L(\hat{p}),
$$

where $H(\hat{q}):=\max _{p \in \Delta^{m}} p A \hat{q}$ and $L(\hat{p}):=\min _{q \in \Delta^{n}} \hat{p} A q$.

Theorem 2.1 $W(p, q) \geq 0$, with equality if and only if $(p, q) \in N E(A)$.

This is a classic result that follows from von Neumann's (1928) maximin theorem. For an exact proof, see a.o. Myerson (1991).

\subsection{Continuous Fictitious Play}

A Continuous Fictitious Play (CFP) in $A$ is a pair $(x(t), y(t))$ of Lebesgue measurable functions $x:[0, \infty) \rightarrow \tilde{I}$ and $y:[0, \infty) \rightarrow \tilde{J}$, such that for almost all $t \geq 1$, we have

$$
(x(t), y(t)) \in \beta\left(\frac{1}{t} \int_{0}^{t} x(\tau) d \tau, \frac{1}{t} \int_{0}^{t} y(\tau) d \tau\right) .
$$

Players' beliefs $(p(t), q(t))$ are defined as functions

$$
p(t):=\frac{1}{t} \int_{0}^{t} x(\tau) d \tau, \text { and } q(t):=\frac{1}{t} \int_{0}^{t} y(\tau) d \tau
$$

on the domain $[1, \infty)$. Furthermore, we define the set $\Omega$ of limit points of $(p(t), q(t))$ as

$$
\Omega:=\bigcap_{T \geq 1} \operatorname{cl}(\{(p(t), q(t)) \mid t \geq T\}),
$$

where $\mathrm{cl}$ denotes the topological closure. We say $(p, q)$ converges to Nash equilibrium if $\Omega \subseteq N E(A, B)$. Expected and average payoffs are defined for $t \in[1, \infty)$ as

$$
E_{1}(t):=x(t) A q(t), \text { and } E_{2}(t):=-p(t) A y(t),
$$

and

$$
P_{1}(t):=\frac{1}{t} \int_{0}^{t} x(\tau) A y(\tau) d \tau, \text { and } P_{2}(t):=-P_{1}(t) .
$$

Monderer et al. (1997) introduce the concept of belief affirmation; a CFP is said to be belief affirming if

$$
\lim _{t \rightarrow \infty}\left(E_{i}(t)-P_{i}(t)\right)=0
$$

for $i=1,2$. In a belief affirming process players' expected payoffs and average realized payoffs coincide in the long run. 


\section{CFP Convergence in Zero-Sum Games}

The aim of this note is to prove the following.

Theorem 3.1 CFP in zero-sum games converges to Nash equilibrium.

The proof is divided into three simple lemmas. The first is due to Monderer et al. (1997). For completeness, we include the proof.

Lemma 3.2 (Monderer et al. 1997) Every CFP is belief affirming.

Proof. Each function $f_{i}:[1, \infty) \rightarrow \mathbb{R}, i \in I$, defined as

$$
f_{i}(t):=\int_{0}^{t} e^{i} A y(\tau) d \tau
$$

is continuous on $[1, \infty)$. Since $t E_{1}(t)=\max \left\{f_{i}(t) \mid i \in I\right\}$ for all $t \geq 1$, also $t E_{1}(t)$ is continuous on $[1, \infty)$. The function $t P_{1}(t)$ is also continuous on $[1, \infty)$; it follows that $t E_{1}(t)-t P_{1}(t)$ is continuous on $[1, \infty)$.

Suppose $(x(\cdot), y(\cdot))$ is continuous at $t$. Since $x(\cdot)$ and $y(\cdot)$ are by definition pure strategies, there is an $\varepsilon>0$ such that $x(\tau)$ and $y(\tau)$ are constant for all $\tau \in(t-\varepsilon, t+\varepsilon)$. This implies that the derivatives of $t E_{1}(t)$ and $t P_{1}(t)$ at $t$ are both equal to $x(t) A y(t)$. It follows that $t E_{1}(t)-t P_{1}(t)$ is constant on each interval on which $(x(\cdot), y(\cdot))$ is continuous. Continuity of $t E_{1}(t)-t P_{1}(t)$ on $[1, \infty)$ then implies

$$
t E_{1}(t)-t P_{1}(t)=K
$$

for all $t \in[1, \infty)$, where $K:=E_{1}(1)-P_{1}(1)$. Thus,

$$
\lim _{t \rightarrow \infty}\left(E_{1}(t)-P_{1}(t)\right)=\lim _{t \rightarrow \infty} \frac{1}{t}\left(t E_{1}(t)-t P_{1}(t)\right)=\lim _{t \rightarrow \infty} \frac{K}{t}=0 .
$$

A similar argument applies to player 2 .

Lemma $3.3 \lim _{t \rightarrow \infty} W(p(t), q(t))=0$.

Proof. It follows from Lemma 3.2 that CFP is belief affirming. This implies

$$
\begin{aligned}
0 & =\lim _{t \rightarrow \infty}\left(E_{1}(t)-P_{1}(t)\right)+\lim _{t \rightarrow \infty}\left(E_{2}(t)-P_{2}(t)\right) \\
& =\lim _{t \rightarrow \infty}\left(E_{1}(t)-P_{1}(t)+E_{2}(t)-P_{2}(t)\right) \\
& =\lim _{t \rightarrow \infty}\left(E_{1}(t)+E_{2}(t)\right) \\
& =\lim _{t \rightarrow \infty} W(p(t), q(t)),
\end{aligned}
$$


where the third equality follows from $P_{1}(t)=-P_{2}(t)$ for all $t$, and the fourth from $W(p(t), q(t))=E_{1}(t)+E_{2}(t)$ for all $t$.

Proof of Theorem 3.1 Take some $\left(p^{*}, q^{*}\right) \in \Omega$ and a sequence of times $\left(t_{k}\right)_{k=1}^{\infty}$ such that $\lim _{k \rightarrow \infty}\left(p\left(t_{k}\right), q\left(t_{k}\right)\right)=\left(p^{*}, q^{*}\right)$. Note that the existence of such a sequence is implied by $\left(p^{*}, q^{*}\right) \in \Omega$. Since $W$ is continuous in $(p, q)$ we have

$$
\lim _{k \rightarrow \infty} W\left(p\left(t_{k}\right), q\left(t_{k}\right)\right)=W\left(p^{*}, q^{*}\right) .
$$

By Lemma 3.3 it follows that $W\left(p^{*}, q^{*}\right)=0$, which by Theorem 2.1 implies $\left(p^{*}, q^{*}\right) \in N E(A)$. Hence, $\Omega \subseteq N E(A)$.

Remark 3.5 From Equation (1) it follows that $\left(E_{1}(t)-P_{1}(t)\right)$ converges at rate $\frac{1}{t}$; this also holds for player 2 . It follows that $(p(t), q(t))$ converges to equilibrium at a rate of $\frac{1}{t}$, confirming Harris' (1998) result.

Remark 3.6 Our proof of Theorem 3.1 seems to be closer to Brown's heuristic argument than the one usually presented in the literature. For instance, Brown (1951, pp. 375) says: ${ }^{3}$ "In the system of differential equations the convergence rests on the fact that $t \bar{V}(t)$ and $t \underline{V}(t)$ maintain a constant difference between them."

\section{DFP in Zero-Sum Games}

A Discrete Fictitious Play (DFP) in $A$ is a sequence $(x(t), y(t))$ in $\tilde{I} \times \tilde{J}, t \in \mathbb{N}$, with $(x(0), y(0)) \in \tilde{I} \times \tilde{J}$ and for all $t \in \mathbb{N} \backslash\{0\}$,

$$
(x(t), y(t)) \in \beta\left(\frac{1}{t} \sum_{\tau=0}^{t-1}(x(\tau), y(\tau))\right) .
$$

The sequence of beliefs $(p(t), q(t)): \mathbb{N} \backslash\{0\} \rightarrow \Delta^{m} \times \Delta^{n}$, is given by

$$
\frac{1}{t} \sum_{\tau=0}^{t-1}(x(\tau), y(\tau))
$$

Like before, we define $E_{1}(t):=x(t) A q(t), E_{2}(t):=-p(t) A y(t)$,

$$
P_{1}(t):=\frac{1}{t} \sum_{\tau=0}^{t-1} x(\tau) A y(\tau), \text { and } P_{2}(t):=-P_{1}(t) .
$$

The following result was proven by Robinson (1951).

\footnotetext{
${ }^{3}$ Here, $\bar{V}(t) \equiv E_{1}(t)$ and $\underline{V}(t) \equiv-E_{2}(t)$.
} 
Theorem 4.1 (Robinson 1951) DFP in zero-sum games converges to Nash equilibrium.

A DFP satisfies the condition of infrequent switching ${ }^{4}$ if

$$
\lim _{t \rightarrow \infty} \frac{1}{t} \sum_{\tau=1}^{t} M_{i}(\tau)=0
$$

for $i=1,2$, where

$$
M_{1}(t):=\left\{\begin{array}{ll}
1 & \text { if } x(t) \neq x(t-1) \\
0 & \text { otherwise. }
\end{array} \quad \text { and } \quad M_{2}(t):= \begin{cases}1 & \text { if } y(t) \neq y(t-1) \\
0 & \text { otherwise }\end{cases}\right.
$$

for all $t \in \mathbb{N} \backslash\{0\}$. Monderer et al. (1997), and Fudenberg and Levine (1994) established the following result.

Lemma 4.2 Every DFP satisfying infrequent switching is belief affirming.

Hence, if the DFP process satisfies infrequent switching, then its convergence in zero-sum games follows along the lines of the previous section. Whether DFP in zero-sum games satisfies infrequent switching remains an open question.

\section{References}

[1] Brown, G. W. (1949). Some notes on computation of games solutions. RAND report P-78, The RAND Corporation, Santa Monica, California.

[2] Brown, G. W. (1951). Iterative solution of games by fictitious play. In T. C. koopmans (Ed.), Activity Analysis of Production and Allocation, Chapter 24, pp. 374-376. Wiley, New York.

[3] Fudenberg, D. and D. K. Levine (1995). Consistency and cautious fictitious play. Journal of Economic Dynamics and Control 19(4), 1065-1089.

[4] Harris, C. (1998). On the rate of convergence of continuous-time fictitious play. Games and Economic Behavior 22(2), 238-259.

[5] Hofbauer, J. and S. Sorin (2006). Best-response dynamics for continuous zero-sum games. Discrete and Dynamical Systems-Series B 6(1), 215-224.

[6] Krishna, V. and T. Sjöström (1997). In S. Hart and A. Mas-Colell (Eds.), Cooperation: Game-theoretic Approaches, Volume 55 of NATO-ASI Series F, pp. 257-273. Springer, Berlin.

[7] Monderer, D., D. Samet, and A. Sela (1997). Belief affirming in learning processes. Journal of Economic Theory 73(2), 438-452.

\footnotetext{
${ }^{4}$ Monderer et al. (1997) call DFP's that satisfy infrequent switching "smooth" Fictitious Plays.
} 
[8] Myerson, R. B. (1991). Game theory: Analysis of conflict. Harvard University Press, Cambridge, Massachusetts.

[9] von Neumann, J. (1928). Zur theorie der gesellschaftsspiele. Mathematische Annalen 100(1), 295-320.

[10] Robinson, J. (1951). An interative method of solving a game. Annals of Mathematics 54(2), 296-301.

[11] Shamma, J. S. and G. Arslan (2004). Unified convergence proofs of continuous-time fictitious play. IEEE Transactions on Automatic Control 49(7), 1137-1142. 